\title{
Management of Traumatic Dental Injuries Using Different Types of Splints: A Case Series
}

\author{
Mridula Goswami ${ }^{1}$, Arshad Eranhikkal ${ }^{2}$
}

\begin{abstract}
Traumatic injuries are described as injuries resulting from external or internal forces that can affect the quality of life of the patients. Different types of facial structures are injured due to traumatic forces. Multiple injuries can occur depending upon intensity of forces. The management of traumatic dental injuries is often difficult. Various types of management techniques have been advocated for comprehensive treatment of traumatic injuries. Splinting has become one of the commonly used methods for management of traumatized teeth. It helps in repositioning and stabilization of teeth. Different types of splints have been used for management of traumatic injuries depending on the type of injury and type of fixation required. The purpose of this case series is to present management of traumatic injuries to anterior teeth in children using different types of splints. Four cases have been included in this case series. Different types of splints have their own advantages and disadvantages and should be applied judiciously depending upon the type and extent of traumatic injuries.
\end{abstract}

Keywords: Dentoalveolar structures, Periodontium, Splinting, Traumatic injuries.

International Journal of Clinical Pediatric Dentistry (2020): 10.5005/jp-journals-10005-1746

\section{INTRODUCTION}

Traumatic injuries to anterior teeth are one of the commonly faced problems faced by young children and adolescents. The main causes for traumatic injuries include accidents, contact sports, falls, and violence. ${ }^{1}$ Trauma incidence in permanent dentition is at its peak between 8 years and 10 years when children start engaging in different types of contact sports. Maxillary central incisors are most commonly affected. ${ }^{2}$ Trauma to periodontal ligament and alveolar bones are also common along with dental trauma. In cases of any trauma to the facial region, the incidence of maxillary anteriors being injured is $37 \%$ as they are most anteriorly placed in the arch which are followed by maxillary laterals (16\%) and mandibular central incisors. ${ }^{3}$ Following orofacial trauma, jaw fractures and dislocation of teeth are the most common findings. Adequate treatment of traumatic injuries is done in children with different types of goals in mind.

Depending upon the type and extent of injuries, several types of techniques have been employed regarding management of traumatic injuries. In most cases, supporting tooth structures are also involved apart from the tooth. Splinting is one of the commonly used technique for repositioning and stabilization of traumatic teeth which improves the healing outcome. A splint has been defined as "an apparatus used to support, protect or immobilize teeth that have been loosened, replanted, fractured or subjected to certain endodontic surgical procedures". ${ }^{4}$ Historically, splinting of teeth were done with rigid splints which required long-term immobilization. This was based on the principles of bone fracture management using rigid techniques. But major drawback of rigid immobilization is that it can cause pulp necrosis and external root resorption. ${ }^{5}$ Later flexible splints were introduced and the reported incidence of ankylosis was less. This suggests that some functional movement of the traumatized teeth should be allowed by the splint used. ${ }^{6}$ If a rigid splint is used, teeth are completely immobilized, whereas a flexible splint allows functional movement. Recent studies reported that, when compared with suture splinting, the ankylosis rate was three times higher with wire and composite resin \begin{tabular}{l}
\hline 1,2Department of Pedodontics and Preventive Dentistry, Maulana Azad \\
Institute of Dental Sciences, New Delhi, India \\
Corresponding Author:Mridula Goswami, Department of Pedodontics \\
and Preventive Dentistry, Maulana Azad Institute of Dental Sciences, \\
New Delhi, India, Phone: +919654700977, e-mail: mm_goswami@ \\
yahoo.com \\
How to cite this article: Goswami M, Eranhikkal A. Management of \\
Traumatic Dental Injuries Using Different Types of Splints: A Case \\
Series. Int J Clin Pediatr Dent 2020;13(2):199-202. \\
Source of support: Nil \\
Conflict of interest: None
\end{tabular}

splinting. This suggests that physiological movement is important for good healing outcomes. According to the International Association of Dental Traumatology (IADT) guidelines, flexible splints used for short duration are more recommended than rigid splints. ${ }^{7}$

The purpose of this case series is to present the advantages and clinical applications of the different types of splints used in traumatic injuries. Proper diagnosis and treatment plan should be made for successful management, and splinting is one of the major factors determining successful treatment outcome.

\section{Case Descriptions}

Four cases are discussed under this case series. The patients reported to the Department of Pedodontics and Preventive Dentistry of Maulana Azad Institute of Dental Sciences, New Delhi. Proper case history was taken in every case along with examination and investigations. Appropriate splints were used in different cases per requirement.

\section{Case 1}

A 12-year-old boy reported to the department, with a history of fall while playing. On examination, lacerations were present on 
chin and lips (Fig. 1). Both the maxillary central incisors had Ellis class VII fracture without root fracture. Along with this, fracture of crown of 21 was also noted. Under local anesthesia, teeth were repositioned. Splint was applied with the help of stainless steel wire and composite resin material for 3 weeks (Fig. 2). Root canal treatment was started in 21. Oral hygiene instructions were advised for the proper maintenance of the splint. After 3 weeks, patient was examined clinically and radiographically. Eventually, the splint was removed. Occlusion was normal and soft tissues were healed properly.

\section{Case 2}

A 13-year-old boy reported to the department, with a history of trauma due to motor vehicle accident. On clinical examination, laceration on lower lips was present and there was fracture of tooth in upper arch (Fig. 3). Both maxillary central incisors had Ellis class VII fracture. Periapical radiographic examination showed Ellis class III fracture of 22 without root fracture. Under local anesthesia, repositioning of the teeth was done, and a flexible splint was applied with help of fiber splint (Ribbond) for 3 weeks (Fig. 4). Oral hygiene instructions were advised which was essential for the maintenance of the splint. Clinical and radiographic examination were done after

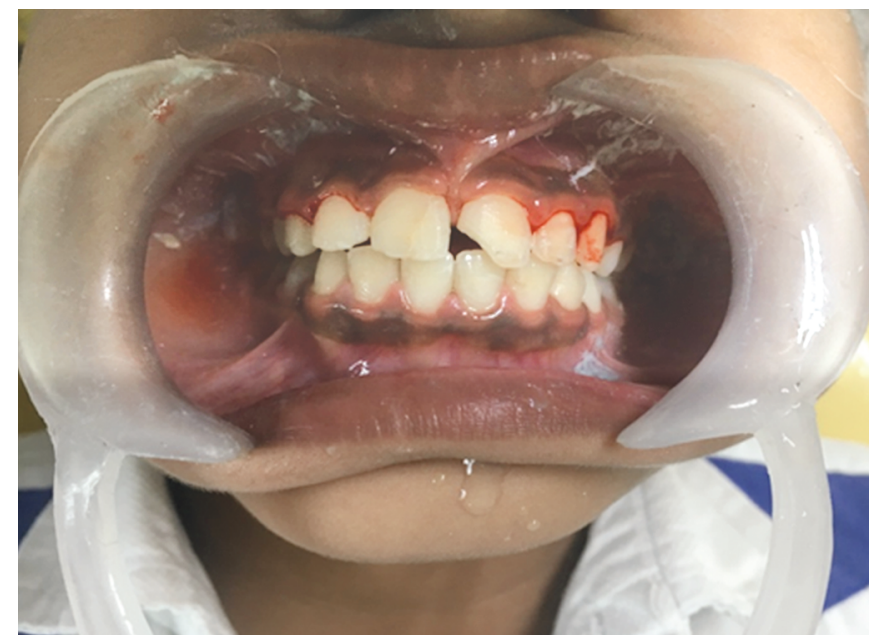

Fig. 1: Preoperative view (Case 1)

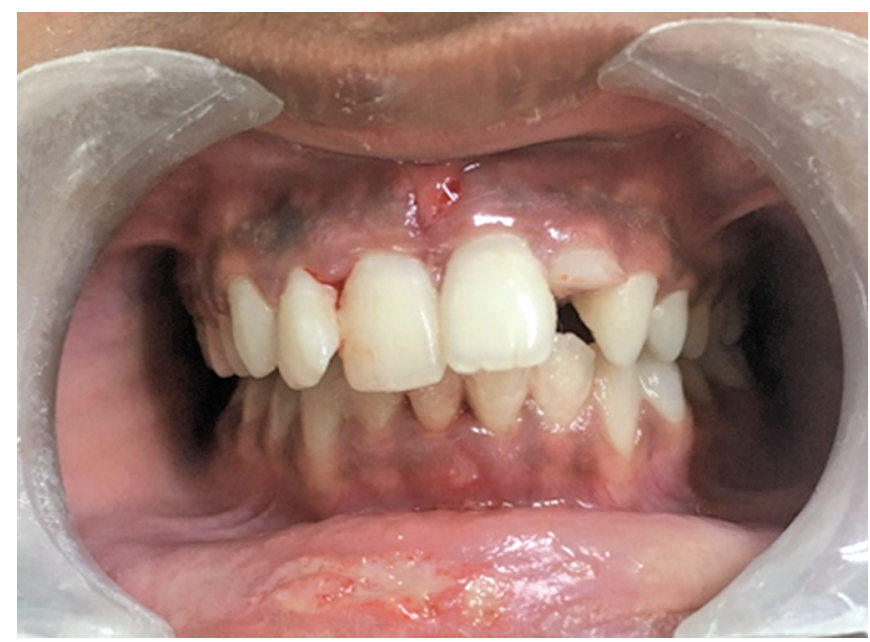

Fig. 3: Preoperative view (Case 2)
3 weeks which showed periodontal and bone healing. The splint was removed and normal occlusion was established.

\section{Case 3}

A 4-year-old boy reported to the department, with a history of trauma due to fall inside the home. He neither had history of loss of consciousness nor vomiting. Extraoral examination was done and temporomandibular joint palpation revealed no disturbances. Lower lip swelling was seen on intraoral examination, hematoma was seen on the floor of the mouth, soft tissue lacerations, and displacement of mandibular right lateral incisor and canine were also present. Occlusion was also disturbed. Orthopantomogram (OPG) was taken, which showed presence of fracture line between 82 and 83, which indicate fracture of mandible at right parasymphyseal region. Upper and lower impressions were taken with alginate and acrylic splint was made (Fig. 5). Splint was fixed for 3 weeks. Clinical and radiographic examination done after 3 weeks revealed reduced mobility and hence the splint was removed.

\section{Case 4}

A 10-year-old boy was brought to the department, with a history of trauma due to fall during playing. Intraoral examination revealed

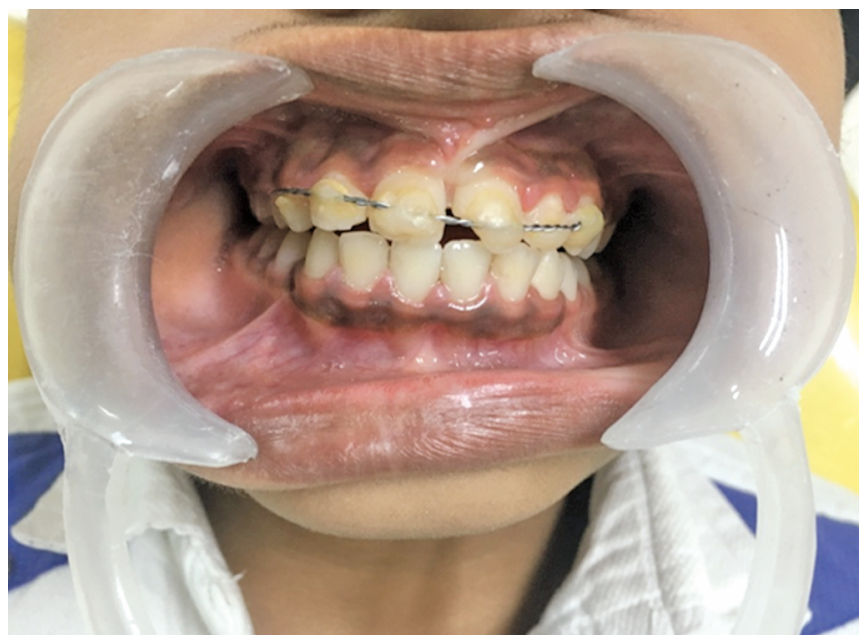

Fig. 2: Wire and composite resin splint placed (Case 1)

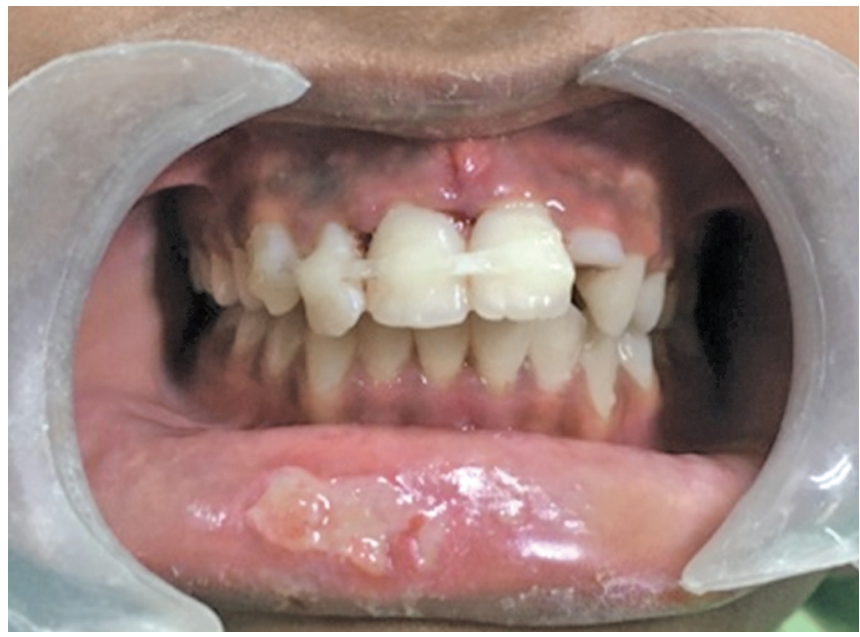

Fig. 4: Fiber splinting done with Ribbond (Case 2) 


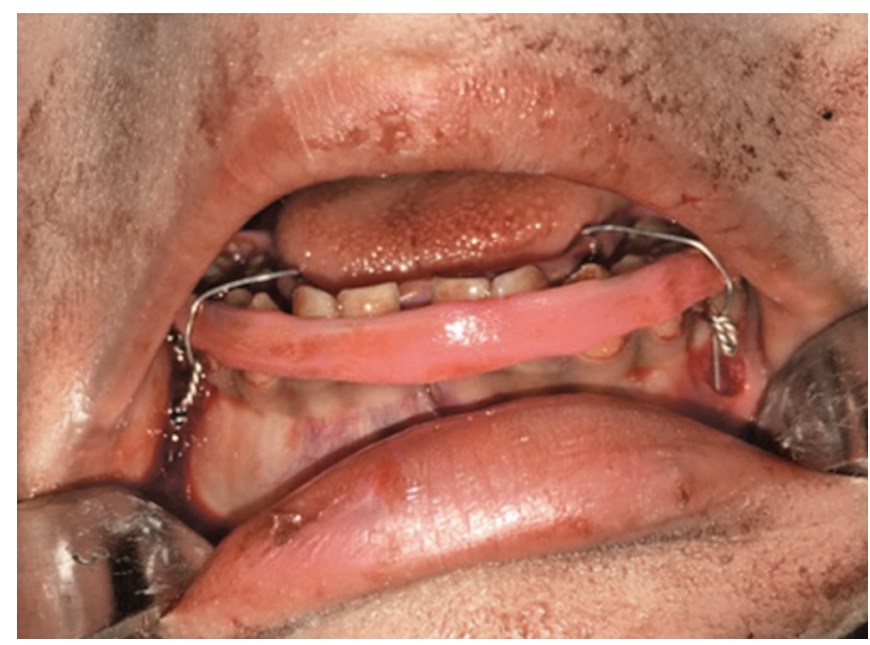

Fig. 5: Cap splint done (Case 3)

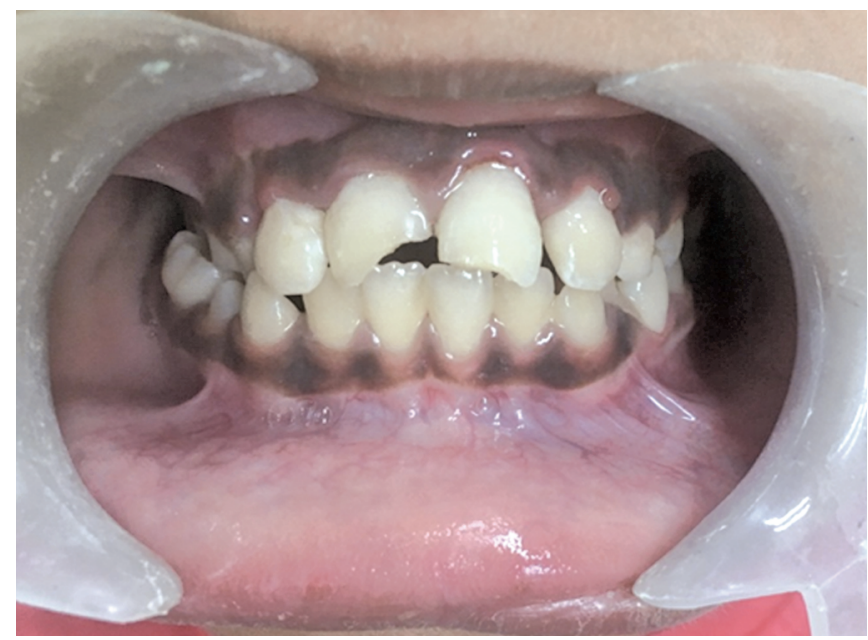

Fig. 7: Splint removal done (Case 4)

Ellis class $V$ fracture of 21 but was not detached from the gingiva. Ellis class II fracture of 11 was present. Clinical and radiographic examination of maxillofacial region was done and no fractured segments were noted. The treatment plan was to reposition the tooth using arch bar fixation (Fig. 6). Splinting was removed after 3 weeks (Fig. 7), and the patient was asymptomatic and the tooth were planned for restoration with composite restorations.

\section{Discussion}

Injuries to facial structures are one of the commonest injuries occurring in children. Along with tooth, supporting structures such as alveolar bone, periodontal ligament, and cementum are also affected. The prevalence of traumatic dental injuries in children aged 13 years was found to be $10.9 \%{ }^{8}$ in a study conducted by Govindarajan et al. in Chidambaram, Tamil Nadu, India. A study conducted by Kovacs et al. in Targu Mores, Romania, found that the prevalence of traumatic dental injuries in children is $24 \% .{ }^{9}$ Another study conducted by Traebert et al. in Brazil found that prevalence of traumatic dental injuries in children is $18 \% .{ }^{10}$ If luxation injury happens, especially in incisors, they cannot return to their normal alignment in spontaneous manner. Instead, they should be aligned properly in respective position and should be stabilized. Splints

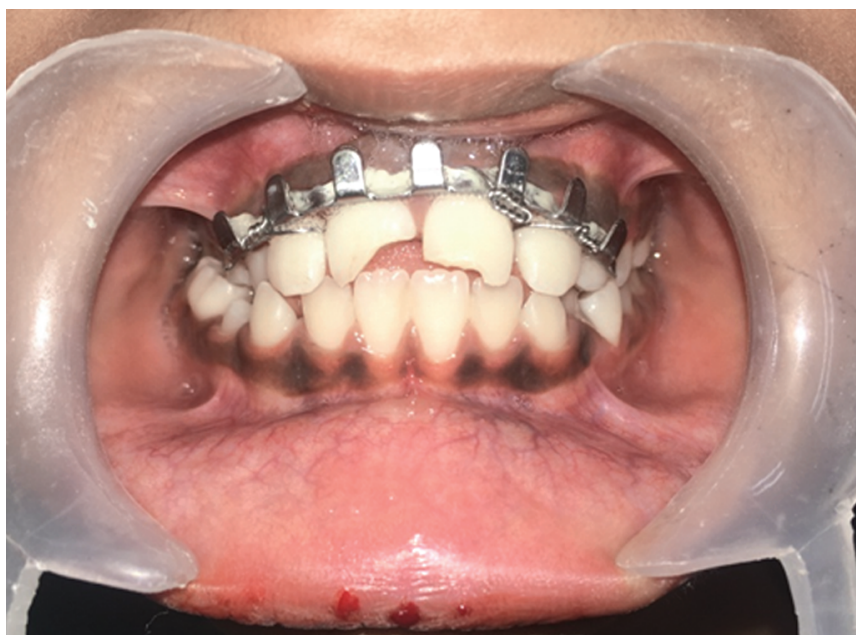

Fig. 6: Arch bar fixation done (Case 4)

are used in such cases in order to bring the teeth back to normal position.

Ideal requirements of a splint as modified from Andreasen's original recommendations in $1972^{11}$ include the following:

- A splint should provide reattachment of periodontal ligament fibers.

- It should avoid further trauma and should prevent swallowing of a loose tooth.

- It can be applied and removed easily without causing additional trauma to the surrounding soft tissues.

- It should stabilize the injured tooth/teeth in its correct position throughout the splinting period.

- It should allow physiologic tooth mobility.

- It should be nonirritating to soft tissues.

- It should allow pulp sensibility testing and endodontic access.

- Maintenance of adequate oral hygiene should be possible.

- Occlusal movements should not be interfered.

- It should fulfill esthetic appearance and should be comfortable for the patient.

Most commonly used splints are the composite and stainless steel wire splints. If the diameter of wire is no greater than $0.3-0.4$ $\mathrm{mm}$, they are termed as flexible splints. These are less irritating to gingival tissues compared to wire and bracket splints. These types of splints can be effectively used in luxation injuries and also for the management of avulsion. The procedures for placement of these splints are very simple and it does not traumatize other teeth. It also helps in maintaining speech and esthetics, and it is easy to maintain the oral hygiene. It does not cause any interference for vitality testing and endodontic procedures.

Fiber splints use a polyethylene or Kevlar fiber mesh. They also contain an unfilled resin such as Optibond ${ }^{\mathrm{TM}}$ FL (Kerr, USA). Different types of fiber splints such as Ribbond ${ }^{\mathrm{TM}}$ (Ribbond Inc., Seattle, USA), Fiber-Splint (Polydentia SA Mezzovico-Vira, Switzerland), EverStick (Stick Tech Ltd, Turku, Finland), etc. are available. Fiber splints can provide increased stabilization of mobile or displaced teeth; and most importantly, they are esthetically acceptable in young children. Moreover, the fixation procedure is very simple, and it does not cause any additional trauma to the surrounding soft tissues. It does not cause any interference for vitality testing and endodontic procedures and helps in maintaining oral hygiene. 
Arch bar splints are usually used in dentoalveolar trauma. Arch bar is a metal bar that can be easily turned into the shape of the arch. It is fixed over the tooth with the help of ligature wires. Main disadvantage of this technique is that rigid splints are used here, which does not allow physiological movement of teeth. If the arch bar is loosened or ligature wires are loose, it can cause irritation of gingival tissues. The arch bar splinting is not commonly used nowadays for the management of traumatic dental injuries. This is because flexible splints are recommended by IADT for all types of traumatic injury classifications. The only exception for this is dentoalveolar fracture.

Acrylic splints are used in complex traumatic cases where dentoalveolar fractures are associated with bony fractures. In the case discussed above, right parasymphyseal fracture was present along with dentoalveolar fracture. This can be used in cases where the fracture lines can be approximated by applying pressure, so that open surgical procedures can be avoided. The procedure is relatively simple and can be used especially in children and young adults.

Pediatric maxillofacial fractures are common and when compared with adults, they demonstrate different clinical features. They also need different treatment plans due to the differences in their facial bones and skulls. Fractures of the alveolar process are more common in children, while midfacial fractures are less common. These characteristic fracture patterns are a consequence of the anatomical characteristics of the pediatric facial skeleton such as the elasticity of the developing jaws, lack of sinus pneumatization, mixed dentition, a prominent forehead as well as the etiology of the trauma.

Complete prevention of accidents are impossible in cases of children, but we can restrict associated complications by adequate treatment and follow-up. So the general dentists and the pediatric dentists should have knowledge of different types of management methods and their application in the treatment of traumatic dental injuries. The prognosis of traumatic injuries may worsen if the right type of treatment is not given at the right time. In case of avulsion management, the treatment plan differs based on the time elapsed after injury. Injury to a young child's teeth and face is traumatic not only in the physical sense but also in the emotional and psychological sense. Noninvasive criteria will be more appropriate when treating a child with acute dental trauma. The patients who have sustained a traumatic dental injury must undergo posttreatment evaluations to assess the initial therapy provided and proceed with an additional phase of treatment of additional problems and to prevent treatment complications.

\section{Conclusion}

Following luxation or avulsion injuries, during the initial period, the use of splint is compulsory for allowing immobilization of the teeth. According to IADT, the use of semirigid splint and flexible splints is more indicated than the rigid one. This is because if splinting is done for long periods, it can cause root resorption or ankylosis. Most of the conventional splinting techniques are esthetically not acceptable by children. Newer splints, which does not use wire components are based on the composites, are esthetically acceptable for the patients, and results in better motivation of child. Regular follow-up of these cases is required in order to avoid further trauma-related complications in the future.

\section{References}

1. Andreasen JO, Andreasen FM, Andersson L. Textbook and color atlas of traumatic injuries to the teeth. 4th ed., Oxford: Blackwell; 2007.

2. Ivancic JN, Bakarcic D, Fugosic V, et al. Dental trauma in children and young adults visiting a university dental clinic. Dent Traumatol 2009;25(1):84-87. DOI: 10.1111/j.1600-9657.2008.00711.x.

3. Kang $Y$, Franco CS. A story of dental injury and orthodontics. Oral Health Dent Manag 2014;13(2):243-253.

4. American Association of Endodontists. Glossary of Endodontic Terms. 8th edn. Available at:URL: 'http://www.nxtbook.com/.nxtbooks/aae/ endodonticglossary/index.php.

5. Oikarinen K. Comparison of the flexibility of various splinting methods for tooth fixation. Int J Oral Maxillofac Surg 1988;17(2):125-127. DOI: 10.1016/s0901-5027(88)80166-8.

6. Geeta T, Preethi S. Managment of complex crown root fracture using fibre post - A case report. Endodontology 2014;26(3):211-216.

7. International Dental Association of Dental Traumatology. Available at: URL: 'http://www.iadt-dentaltrauma.org/1-9\%20\% 20iadt\%20guidelines\%20combined\%20-\%20lr\%20-\%2011-5-2015. pdf'.

8. Govindarajan M, Reddy VN, Ramalingam K, et al. Prevalence of traumatic dental injuries to the anterior teeth among three to thirteen-year-old school children of Tamilnadu. Contemp Clin Dent 2012;3(2):164-167. DOI: 10.4103/0976-237X.96819.

9. Kovacs M, Pacurar M, Petcu B, et al. Prevalence of traumatic dental injuries in children who attended two dental clinics in Targu Mures between 2003 and 2011. Oral Health Dent Manag 2012;11(3):116-124.

10. Traebert J, Peres MA, Blank V, et al. Prevalence of traumatic dental injury and associated factors among 12-year-old school children in Florianópolis, Brazil. Dent Traumatol 2003;19(1):15-18. DOI: 10.1034/j.1600-9657.2003.00138.x.

11. Andreasen JO, Borum M. Replantation of 400 avulsed permanent incisors. Endod Dent Traumatol 1995;11(2):51-58. DOI: 10.1111/j.16009657.1995.tb00461.x. 